\title{
48-Hour Fluid Balance Does Not Predict a Successful Spontaneous Breathing Trial
}

\author{
Ana Carolina Peçanha Antonio MD, Cassiano Teixeira MD PhD, Priscylla Souza Castro MD, \\ Augusto Savi PT PhD, Roselaine Pinheiro Oliveira MD PhD, Marcelo Basso Gazzana MD, \\ and Marli Knorst MD PhD
}

\begin{abstract}
BACKGROUND: Both premature and delayed liberation from mechanical ventilation are associated with increased morbidity and mortality, and fluid balance could negatively influence extubation outcomes. We sought to determine the impact of fluid balance in the $48 \mathrm{~h}$ before a spontaneous breathing trial (SBT) on weaning outcomes in a mixed ICU population. METHODS: This was a prospective observational study in 2 adult medical-surgical ICUs. All enrolled subjects met eligibility criteria for weaning from mechanical ventilation. SBT failure was defined as inability to tolerate a T-piece trial for 30-120 min. Data on demographics, physiology, fluid balance in the $48 \mathrm{~h}$ preceding SBT (fluid input minus output over the 48-h period), lung ultrasound findings, and outcomes were collected. RESULTS: Of a total of 250 SBTs, SBT failure eventuated in $51(20.4 \%)$. Twenty-nine subjects $(11.6 \%)$ had COPD, and 40 subjects $(16 \%)$ were intubated due to respiratory sepsis. One-hundred eighty-nine subjects $\mathbf{( 7 5 . 6 \% )}$ ) were extubated on the first attempt. Compared with subjects with SBT success, SBT failure subjects were younger (median of $66 \mathrm{vs} 75 \mathrm{y}, P=.001$ ) and had a higher duration of mechanical ventilation (median of 7 vs $4 \mathrm{~d}, P<.001$ ) and a higher prevalence of COPD (19.6 vs $9.5 \%, P=.04)$. There were no statistically significant differences in 48-h fluid balance before SBT between groups (SBT failure, 1,201.65 $\pm 2,801.68 \mathrm{~mL}$; SBT success, $1,324.39 \pm 2,915.95 \mathrm{~mL}$ ). However, in the COPD subgroup, we found a significant association between positive fluid balance in the $48 \mathrm{~h}$ before SBT and SBT failure (odds ratio of 1.77 [1.24-2.53], $P=.04$ ). CONCLUSIONS: Fluid balance should not delay SBT indication because it does not predict greater probability of SBT failure in the medical-surgical critically ill population. Notwithstanding, avoiding positive fluid balance in patients with COPD might improve weaning outcomes. (ClinicalTrials.gov registration NCT02022839.) Key words: ventilator weaning; fluid balance; chronic obstructive pulmonary disease; cardiac failure. [Respir Care 2015;60(8):1091-1096. () 2015 Daedalus Enterprises]
\end{abstract}

\section{Introduction}

Imprecise definition of weaning from mechanical ventilation prevents the rigor of research in this area and in-

Drs Antonio, Teixeira, Castro, Savi, Oliveira, and Gazzana are affilaiated with the Adult Intensive Care Unit, Hospital Moinhos de Vento, Porto Alegre, Brazil. Drs Antonio and Castro are also affiliated with the Adult Intensive Care Unit, Hospital Mãe de Deus and Hospital de Clínicas de Porto Alegre, Porto Alegre, Brazil. Dr Knorst is affiliated with the Postgraduate Program in Pneumology, Universidade Federal do Rio Grande do Sul, Porto Alegre, Brazil.

The authors have disclosed no conflicts of interest.

Correspondence: Ana Carolina Peçanha Antonio MD, 11 Ari Marinho, Apartment 210, Porto Alegre 90520-300, Brazil. E-mail: ana.carolina. antonio@gmail.com. terpretation of findings. ${ }^{1}$ Both premature and delayed discontinuation of mechanical ventilation have been associated with increased mortality (36\%), ${ }^{2}$ assuming that re-intubation is not related to upper-airway obstruction. ${ }^{3}$ Early identification of patients who are able to breathe spontaneously results in a shorter duration of mechanical ventilation and lower complication rates. ${ }^{4}$ Incidence of ventilator-associated pneumonia is estimated to be $1-3 \%$ each day on mechanical ventilation. ${ }^{5}$

Switching a patient from positive-pressure ventilation to spontaneous breathing reestablishes negative inspiratory

DOI: $10.4187 /$ respcare.0317210.4187/respcare.03172 
intrathoracic pressure, thus increasing venous return (leftventricular preload), central blood volume, and left-ventricular afterload. This normal condition, often an effort test for the patient, can decompensate cardiorespiratory function in cases of volume overload and left-ventricular systolic or diastolic dysfunction. ${ }^{6}$ Also, in patients with preexisting right-ventricular disease, an increase in weaning-induced right-ventricular afterload may occur as a consequence of hypoxemia or worsening of intrinsic PEEP, especially in the COPD population. ${ }^{7}$ In addition to a simultaneous increase in systemic venous return, higher rightventricular afterload may lead to marked right-ventricular enlargement during weaning, thus impeding the diastolic filling of the left ventricle through a biventricular interdependence mechanism.

\section{See the Related Editorial on Page 1213}

Previous observational studies ${ }^{8-10}$ on weaning procedures found a correlation between higher fluid balance and extubation failure. However, there was considerable diversity in terms of populations evaluated, weaning and extubation protocols, and outcomes analyzed. Furthermore, spontaneous breathing trials (SBTs) were not discriminated among outcomes. A randomized controlled trial showed that fluid management guided by brain natriuretic peptide plasma concentrations reduced time to weaning, ${ }^{11}$ despite similar fluid balance between groups on the day of extubation. Empirically and unnecessary administration of diuretics in every ready-to-wean patient has become more and more frequent, even though extracardiac causes are responsible for weaning failure in at least $50 \%$ of cases, and $\sim 70 \%$ of patients are successfully extubated on the first attempt (simple weaning). Moreover, uncontrolled diuretic therapy may have potentially harmful effects, such as serious electrolyte disturbances and microatelectasis related to bronchiolar obstruction by dry bronchial secretions. $^{7}$

We therefore hypothesized that fluid balance should not delay the decision to submit the ordinary mechanically ventilated patient to an SBT because it cannot accurately predict the earliest time that a individual might resume spontaneous breathing. The objective of our study was to prospectively assess the variables associated with SBT failure in a heterogeneous group of mechanically ventilated subjects.

\section{Methods}

Between January 2011 and March 2013, nonconsecutive subjects $>18$ y of age who had undergone invasive mechanical ventilation for $24 \mathrm{~h}$ were enrolled from mixed ICUs in 2 private hospitals. Patients with a tracheostomy were excluded. The research ethics board at each center

\section{QUICK LOOK}

\section{Current knowledge}

Early and delayed discontinuation of mechanical ventilation are associated with significant morbidity and mortality. Delayed discontinuation may result from insufficient screening processes or failure to recognize disease resolution. A positive fluid balance may impact resolution of lung disease, diminish lung compliance, and delay weaning.

\section{What this paper contributes to our knowledge}

Fluid balance in the preceding $48 \mathrm{~h}$ before extubation did not impact weaning outcomes in a group of medical-surgical subjects. Subjects with COPD appeared to benefit from fluid restriction before extubation.

approved the study and waived the requirement for informed consent. The study was registered as NCT02022839 at ClinicalTrials.gov.

Subjects were assessed daily for eligibility to wean according to: (1) improvement in underlying condition that led to acute respiratory failure, (2) alertness and ability to communicate, (3) adequate gas exchange as indicated by a $\mathrm{P}_{\mathrm{aO}_{2}}$ of at least $60 \mathrm{~mm} \mathrm{Hg}$ with an $\mathrm{F}_{\mathrm{IO}_{2}}$ of $<0.40$, (4) rapid shallow breathing index of $\leq 105$, and (5) vasoactive drugs at low and stable doses (norepinephrine doses of $<0.12$ $\mu \mathrm{g} / \mathrm{kg} / \mathrm{min}$ or equivalent dopamine doses).

The main outcome of interest was SBT failure, defined as inability to tolerate a T-piece trial of spontaneous breathing for 30-120 min, in which case, subjects were not extubated. The breathing trial was interrupted if the subject developed signs of respiratory discomfort (breathing frequency of $>38$ breaths/min, arterial oxyhemoglobin saturation of $<90 \%$, use of accessory respiratory muscles, or paradoxical thoracoabdominal ventilation), tachycardia (heart rate of $>130$ beats/min), hemodynamic instability (systolic blood pressure of $<90 \mathrm{~mm} \mathrm{Hg}$ or $20 \%$ over basal levels), or change in mental status (drowsiness, coma, anxiety).

Demographic data, including age, sex, race, comorbidities, severity of illness at the time of ICU admission, reason for the initiation of mechanical ventilation, physiological weaning predictors, last chest radiograph findings available before SBT, and fluid balance in the $48 \mathrm{~h}$ preceding SBT, were recorded. The presence of diastolic or systolic left-ventricular dysfunction (the latter condition defined as an ejection fraction of $<45 \%$ ) was documented according to echocardiogram reports dated up to 6 months before admission. Diagnosis of COPD was based on history, physical examination, chest radiograph, and previous pulmonary function tests. 


\section{8-h Fluid Balance Does Not Predict a Successful SBT}

Table 1. Characteristics of the Study Cohort

\begin{tabular}{|c|c|c|c|}
\hline Characteristic & SBT Success $(n=199)$ & SBT Failure $(n=51)$ & $P$ \\
\hline Age, y & $75(60-83)$ & $66(47-81)$ & .03 \\
\hline Females, \% & 42.2 & 45.1 & .71 \\
\hline APACHE II score & $20.8 \pm 6.9$ & $21.8 \pm 7.8$ & .25 \\
\hline SOFA score & $5(3-9)$ & $5(2-9)$ & .9 \\
\hline BMI, $\mathrm{kg} / \mathrm{m}^{2}$ & $25(23-30)$ & $25(23-29)$ & .82 \\
\hline $\mathrm{RSBI}, \mathrm{f} / \mathrm{V}_{\mathrm{T}}$ & $58.3 \pm 24.3$ & $58.4 \pm 24$ & .89 \\
\hline Mechanical ventilation duration, days & $4(2-6)$ & $7(4-11)$ & $<.001$ \\
\hline \multicolumn{4}{|l|}{ Comorbidities, $n(\%)$} \\
\hline COPD & $19(9.5)$ & $10(19.6)$ & .04 \\
\hline Ejection fraction $<45 \%$ & $19(9.5)$ & $6(11.8)$ & .64 \\
\hline Left-ventricular diastolic dysfunction & $73(65.8)$ & $15(51.7)$ & .16 \\
\hline Ischemic coronary disease & $36(18.1)$ & $5(9.8)$ & .15 \\
\hline Renal replacement therapy & $34(17.1)$ & $13(25.5)$ & .17 \\
\hline Presence of ascites & $7(3.5)$ & $3(5.9)$ & .44 \\
\hline \multicolumn{4}{|l|}{ Reason for mechanical ventilation, $n(\%)$} \\
\hline Respiratory sepsis & $31(15.6)$ & $9(17.6)$ & .72 \\
\hline Non-respiratory sepsis & $52(26.1)$ & $12(23.5)$ & .7 \\
\hline Congestive heart failure & $20(10.1)$ & $2(3.9)$ & .17 \\
\hline Coma & 39 (19.6) & $6(11.8)$ & .2 \\
\hline Postoperative ARF & $15(7.5)$ & $4(7.8)$ & .94 \\
\hline COPD/asthma & $2(1)$ & $2(3.9)$ & .14 \\
\hline Pulmonary embolism & $6(3)$ & $1(2)$ & .68 \\
\hline ARDS & $10(5)$ & $5(9.8)$ & .2 \\
\hline Simple weaning, $n(\%)$ & $151(75.9)$ & $38(74.5)$ & .61 \\
\hline \multicolumn{4}{|l|}{ Chest radiograph, $n(\%)$} \\
\hline Pleural effusion & $60(30.2)$ & $17(33.3)$ & .66 \\
\hline Pulmonary edema & $56(26.6)$ & $18(35.3)$ & .22 \\
\hline Vasopressor, $n(\%)$ & $39(19.6)$ & $5(9.8)$ & .1 \\
\hline Vasodilator, $n(\%)$ & $13(6.5)$ & $3(5.9)$ & .87 \\
\hline $\begin{array}{l}N=250 . \text { Data are presented as median (interquartile } \\
\text { SBT }=\text { spontaneous breathing trial } \\
\text { APACHE II = Acute Physiology and Chronic Health } \\
\text { SOFA = Sequential Organ Failure Assessment } \\
\text { BMI = body mass index } \\
\text { RSBI = rapid shallow breathing index } \\
\text { f/ } \mathrm{V}_{\mathrm{T}}=\text { breathing frequency/tidal volume } \\
\mathrm{ARF}=\text { acute respiratory failure }\end{array}$ & ot indicated otherwise. & & \\
\hline
\end{tabular}

Fluid balance was routinely recorded on report sheetsand was defined as total input minus total output (tallied daily at midnight). Losses via urinary, gastrointestinal, or other drainage tubes were subtracted from all fluids, nutrition, medications, and blood products administered, whatever the route of administration.

\section{Statistics}

On the basis of the results of Upadya et al, ${ }^{8}$ who observed a 1,500-mL higher fluid balance in the SBT failure group compared with the SBT success group in the $48 \mathrm{~h}$ before extubation, we estimated that 250 subjects would have $91 \%$ power to show the same difference at a 2 -sided $\alpha$ level of 0.05 . Results are expressed as the mean $\pm \mathrm{SD}$, median and interquartile range, and proportions as appro- priate. The normal distribution of the various parameters was investigated observing the distribution of data and using the Kolmogorov-Smirnov test. We used the Student $t$ test or the Mann-Whitney $U$ test to compare continuous variables, and the chi-square test or the Fisher exact test to compare proportions as appropriate. The primary end point was also analyzed in the 3 predefined subgroups: COPD, left-ventricular systolic dysfunction (defined as an ejection fraction of $<45 \%$ ), and isolated left-ventricular diastolic dysfunction. Receiver operating characteristic curves were generated for these subgroups, comparing their ability to discriminate between SBT success and failure subjects according to fluid balance values. Finally, all subjects were divided into categories according to fluid balance in the $48 \mathrm{~h}$ before SBT using arbitrary steps of $1,000 \mathrm{~mL}$ as described by Frutos-Vivar et al. ${ }^{10}$ 


\section{Results}

We obtained complete data in 250 weaning procedures. Overall, SBT failure occurred in 51 subjects (20.4\%). Table 1 shows the baseline characteristics of the study cohort according to outcome. Subjects who were successfully extubated were older (median of 75 vs $66 \mathrm{y}, P=.001$ ) and had been intubated for a shorter duration (mechanical ventilation median of 4 vs $7 \mathrm{~d}, P<.001$ ). There was also a lower prevalence of COPD in the SBT success group (19.6 vs $9.5 \%, P=.04$ ).

Fluid balance in the $48 \mathrm{~h}$ preceding SBT was similar between groups $(1,324.39 \pm 2,915.95$ vs $1,201.65 \pm$ $2,801.68 \mathrm{~mL}$ for the SBT success and failure subjects, respectively; $P=.52$ ) (Fig. 1). Using arbitrary steps of $1,000 \mathrm{~mL}$, the prevalence of SBT failure demonstrated a random distribution among categories (Fig. 2).

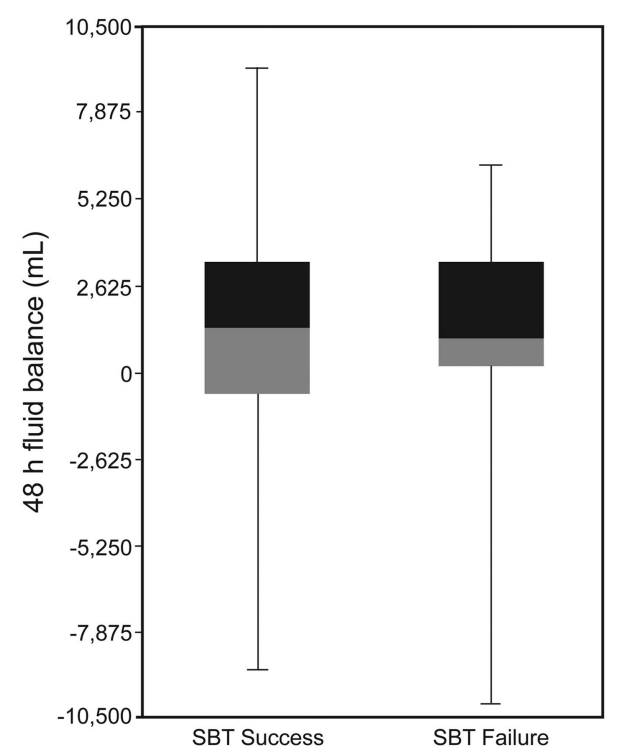

Fig. 1. Forty-eight hours fluid balance according to spontaneous breathing trial (SBT) outcomes ( $P=.52$ between SBT success and failure). Box plots denote the median and interquartile range; points show the maximum and minimum for each group.
The results from subgroup analysis of subjects with COPD, left-ventricular systolic dysfunction, and isolated left-ventricular diastolic dysfunction are shown in Table 2. An area under the receiver operating characteristic curve of $0.70(0.50-0.89)$ was found in subjects with COPD with a cutoff of $0 \mathrm{~mL}$ to SBT failure. Therefore, comparing individuals with 48-h fluid balance above and below the 0 -mL cutoff according to SBT outcomes resulted in a significant association between positive fluid balance in the $48 \mathrm{~h}$ preceding SBT and SBT failure in this subgroup (odds ratio of 1.77 [1.24-2.53], $P=.04$ ), as shown in Figure 3 . The areas under the receiver operating characteristic curve were 0.59 and 0.50 for left-ventricular systolic dysfunction and isolated left-ventricular diastolic dysfunction, respectively.

\section{Discussion}

In a heterogeneous cohort of mechanically ventilated subjects who were candidates for SBT, we found no association between fluid balance in the preceding $48 \mathrm{~h}$ and SBT outcomes. However, subjects with COPD might derive some benefit in terms of not allowing positive fluid balance, probably due to heart-lung interaction issues.

Despite the relationship between failure to wean from mechanical ventilation and positive fluid balance, there is

Table 2. Fluid Balance and Outcomes According to Specific Subgroups

\begin{tabular}{|c|c|c|c|}
\hline \multirow{2}{*}{ Characteristic } & \multicolumn{2}{|c|}{ Fluid Balance (mL) } & \\
\hline & SBT Success $(n)$ & SBT Failure $(n)$ & \\
\hline Ejection fraction $<45 \%$ & $1,096 \pm 3,062(19)$ & $1,804 \pm 1,264(6)$ & \\
\hline $\begin{array}{l}\text { Left-ventricular diastolic } \\
\text { dysfunction }\end{array}$ & $1,241 \pm 2,782(73)$ & $996 \pm 1,899(15)$ & \\
\hline COPD & $1,091 \pm 2,195(19)$ & $2,399 \pm 1,533(10)$ & \\
\hline
\end{tabular}

Values are presented as mean $\pm \mathrm{SD}$

$\mathrm{SBT}=$ spontaneous breathing trial

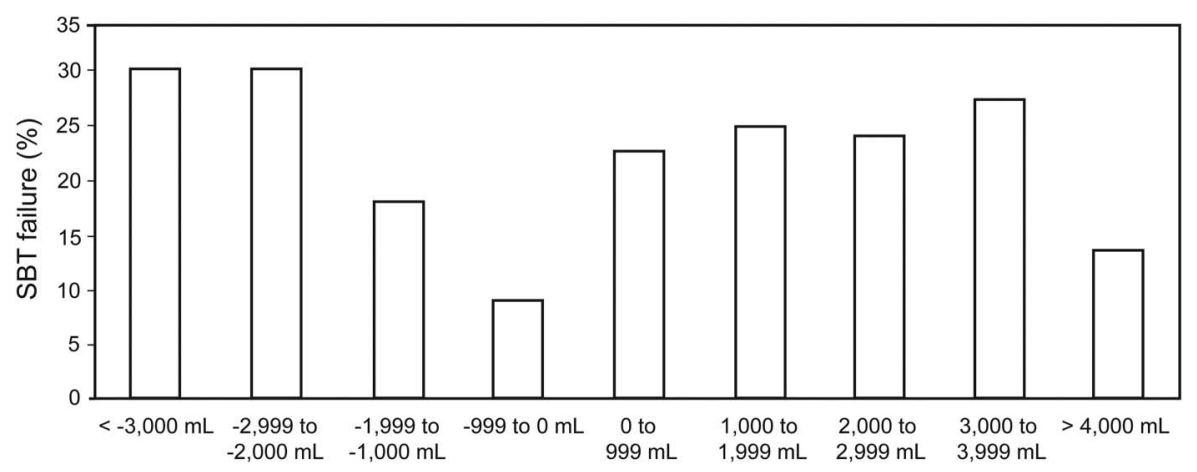

Fig. 2. Prevalence of weaning failure by fluid balance category. Subjects were divided into categories using arbitrary steps of $1,000 \mathrm{~mL}$. Columns depict the spontaneous breathing trial (SBT) failure rate for each category. Note its random distribution, with no more preponderance of SBT failure in either positive or negative fluid balance values. 
no clear evidence of principle cause and effect, and outcomes employed are diverse among studies (weaning, extubation, or both). A central question for clinicians is whether extubation failure is simply a marker of poor prognosis or instead contributes to induce a poor prognosis. ${ }^{12}$ A retrospective analysis of the Vasopressin and Septic Shock Trial (VASST) demonstrated that mortality increases with positive fluid balance in a linear manner independent of severity of illness or shock, and this dose-response correlation was found only $12 \mathrm{~h}$ after study enrollment. ${ }^{13}$ Whether fluid balance independently affects outcome or is just a confounder (a marker of severity of illness) remains unclear, but clearly, aggravating fluid balance by using the wrong tools and the wrong end points should not take place in the context of current knowledge.

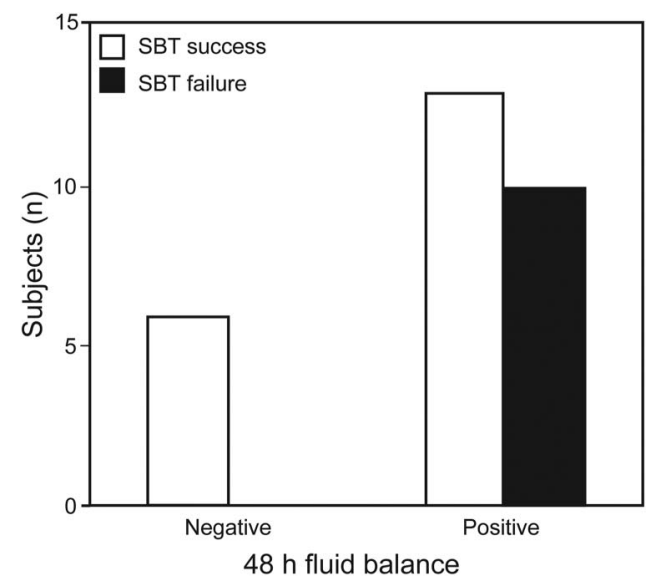

Fig. 3. Association between positive fluid balance in the $48 \mathrm{~h}$ preceding T-piece testing and spontaneous breathing trial (SBT) failure in subjects with COPD (odds ratio of 1.77 [1.24-2.53], $P=.04$ ).
Inaccuracies in monitoring and recording fluid therapy in daily practice are a growing issue in the intensive care setting due to the lack of agreement for standardized body weight measurements. ${ }^{14-16}$ All of the studies neglected to consider nutritional aspects, and some did not take into account the sensible or insensible fluid losses. Average daily and cumulative fluid balances were arithmetically incorrect in about one third of cases. ${ }^{15}$ We could even question the clinical importance or significance of changes in total body water, as the volume load of specific compartments (intravascular volume, cardiac preload, extravascular lung water) is probably more relevant.

Upadya et al $^{8}$ examined 87 subjects who underwent 205 breathing trials (T-piece or pressure support) between 2002 and 2003 and verified that negative fluid balance in the preceding 24 or $48 \mathrm{~h}$ and the net negative cumulative balance were associated with weaning success. The sample contained a high percentage $(46 \%)$ of subjects with COPD, and only $44 \%$ was classified as simple to wean. Although administration of diuretics was associated with negative fluid balance, it was not associated with weaning outcomes. A prospective study of 40 trauma and surgical subjects who were at least $60 \mathrm{y}$ old also proposed a direct relationship between negative fluid balance and weaning success; nevertheless, the weaning failure group already had a fluid balance significantly higher at entry into the study. ${ }^{9}$ Frutos-Vivar et al ${ }^{10}$ published a representative cohort study of 900 subjects, searching for risk factors predicting extubation failure following an SBT and concluded that re-intubated subjects were more likely to have a positive fluid balance in the $24 \mathrm{~h}$ before extubation. Finally, a randomized controlled trial showed that fluid management guided by brain natriuretic peptide plasma concentrations

Table 3. Comparison of Studies

\begin{tabular}{|c|c|c|c|c|}
\hline Parameter & This study & Upadya et $\mathrm{al}^{8}$ & Frutos-Vivar et al ${ }^{10}$ & Mekontso Dessap et al ${ }^{11}$ \\
\hline Sample size, $n$ & 250 & 205 & 900 & 302 \\
\hline Study design & Observational & Observational & Observational & RCT \\
\hline Method of weaning & T-piece & PSV or T-piece & T-piece, PSV, CPAP, flow-by & Automated weaning system \\
\hline Outcome & SBT failure & Extubation failure & Extubation failure & Time to extubation \\
\hline APACHE II score & 21 & 17 & 37 & NA \\
\hline Median age, y & 72 & 66 & 58 & 66 \\
\hline COPD, \% & 11.6 & 46 & NA & 26 \\
\hline Left-ventricular dysfunction, $\%$ & 39.6 & 69 & NA & 14.5 \\
\hline Simple weaning, $\%$ & 75.9 & 45 & NA & NA \\
\hline Median mechanical ventilation, $\mathrm{d}$ & 4 & 3 & 5 & 6 \\
\hline BNP levels & NA & NA & NA & Decrease in successfully weaned subjects \\
\hline \multicolumn{5}{|c|}{$\begin{array}{l}\text { RCT }=\text { randomized control trial } \\
\text { PSV = pressure support ventilation } \\
\text { SBT = spontaneous breathing trial } \\
\text { APACHE II = Acute Physiology and Chronic Health Evaluation II } \\
\text { NA = not available } \\
\text { BNP = brain natriuretic peptide }\end{array}$} \\
\hline
\end{tabular}




\section{8-h Fluid Balance Does Not Predict a Successful SBT}

reduced time to weaning, ${ }^{11}$ a benefit observed predominantly in subjects with left-ventricular systolic dysfunction in a subgroup analysis, regardless of the lack of a significant difference in fluid balance between the standard-care and intervention groups on the day of extubation.

A comparison of our study design with the others mentioned above is shown in Table 3 . Note our higher prevalence of simple weaning, as described in literature, and use of SBT failure as an outcome instead extubation failure. We chose SBT failure as principal outcome because we aimed to predict the earliest time that a patient might resume spontaneous breathing. Moreover, the exact reason for extubation failure often escapes identification. Re-intubation is usually performed because of an apparently new episode of respiratory distress, which may be related to primary respiratory failure, congestive heart failure, aspiration, ineffective cough with airway secretion buildup, or upper-airway obstruction. Other reasons for re-intubation include the onset of new sepsis, surgical complications, acute coronary syndrome, and neurological impairment. This multiplicity of causative factors helps to explain the clinical difficulties raised by extubation and the persistent uncertainties about the pathophysiology of extubation failure. ${ }^{1}$

Limitations of our study include observational design, with all its intrinsic methodological flaws, and small sample size with a high prevalence of elderly population and a lower prevalence of COPD compared with other similar studies. Also, there is potential for inaccuracy and lack of precision of clinical data retrieved from daily flow sheets.

On January 28, 2013, we received 10 patients who were rescued from the Kiss nightclub fire in Santa Maria, Rio Grande do Sul, Brazil. They were between 17 and 23 y of age and had smoke inhalation injury. Six patients failed the Tpiece test at least once. By excluding these patients, there would be no statistically difference in age $(P=.21)$ or fluid balance $(P=.52)$ between SBT failure and success groups.

\section{Conclusions}

In summary, fluid balance may not predict SBT outcomes in a mixed medical-surgical ICU population.

\section{REFERENCES}

1. Tobin M. Principles and practice of mechanical ventilation, 3rd edition. New York: McGraw-Hill; 2012; 1185-1220.

2. Epstein SK. Extubation. Respir Care 2002;47(4):483-492; discussion 493-495.

3. Boles JM, Bion J, Connors A, Herridge M, Marsh B, Melot C, et al. Weaning from mechanical ventilation. Eur Respir J 2007;29(5):10331056.

4. Ely EW, Baker AM, Dunagan DP, Burke HL, Smith AC, Kelly PT, et al. Effect on the duration of mechanical ventilation of identifying patients capable of breathing spontaneously. N Engl J Med 1996; 335(25):1864-1869.

5. Cook DJ, Walter SD, Cook RJ, Griffith LE, Guyatt GH, Leasa D, et al. Incidence of and risk factors for ventilator-associated pneumonia in critically ill patients. Ann Intern Med 1998;129(6):433-440.

6. Perren A, Brochard L. Managing the apparent and hidden difficulties of weaning from mechanical ventilation. Intensive Care Med 2013; 39(11):1885-1895

7. Teboul JL, Monnet X, Richard C. Weaning failure of cardiac origin: recent advances. Crit Care 2010;14(2):211.

8. Upadya A, Tilluckdharry L, Muralidharan V, Amoateng-Adjepong Y, Manthous CA. Fluid balance and weaning outcomes. Intensive Care Med 2005;31(12):1643-1647.

9. Epstein CD, Peerless JR. Weaning readiness and fluid balance in older critically ill surgical patients. Am J Crit Care 2006;15(1):54-64.

10. Frutos-Vivar F, Ferguson ND, Esteban A, Epstein SK, Arabi Y, Apezteguía $\mathrm{C}$, et al. Risk factors for extubation failure in patients following a successful spontaneous breathing trial. Chest 2006;130(6):1664-1671.

11. Mekontso Dessap A, Roche-Campo F, Kouatchet A, Tomicic V, Beduneau G, Sonneville R, et al. Natriuretic peptide-driven fluid management during ventilator weaning: a randomized controlled trial. Am J Respir Crit Care Med 2012;186(12):1256-1263.

12. Thille AW, Richard JC, Brochard L. The decision to extubate in the intensive care unit. Am J Respir Crit Care Med 2013;187(12):12941302.

13. Boyd JH, Forbes J, Nakada TA, Walley KR, Russell JA. Fluid resuscitation in septic shock: a positive fluid balance and elevated central venous pressure are associated with increased mortality. Crit Care Med 2011;39(2):259-265.

14. Johnson R, Monkhouse S. Postoperative fluid and electrolyte balance: alarming audit results. J Perioper Pract 2009;19(9):291-294.

15. Perren A, Markmann M, Merlani G, Marone C, Merlani P. Fluid balance in critically ill patients. Should we really rely on it? Minerva Anestesiol 2011;77(8):802-811.

16. Schneider AG, Baldwin I, Freitag E, Glassford N, Bellomo R. Estimation of fluid status changes in critically ill patients: fluid balance chart or electronic bed weight? J Crit Care 2012;27(6): 745.e7-745.e12.

This article is approved for Continuing Respiratory Care Education credit. For information and to obtain your CRCE

(free to AARC members) visit

www.rcjournal.com

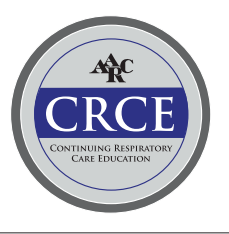

